\title{
Characteristic patterns of emergency ambulance assignments for older adults compared with adults requiring emergency care at home in Sweden: a total population study
}

\author{
Anna Hjalmarsson ${ }^{1 *}$ D, Mats Holmberg ${ }^{2,3,4}$, Margareta Asp ${ }^{1}$, Gunnel Östlund ${ }^{1}$, Kent W. Nilsson ${ }^{1,5}$ and
} Birgitta Kerstis ${ }^{1}$

\begin{abstract}
Background: Since the vast majority of older adults in Sweden live in their private homes throughout life, the emergency medical services need to adapt accordingly. Hence, we aimed to describe characteristic patterns of dyadic staffed emergency ambulance assignments for older adults aged $>70$ years compared with adults aged 1869 years requiring emergency care at home in Sweden.

Methods: A descriptive retrospective study was performed using anonymized registry data from the emergency medical services in a region of Sweden during 2017-2018. One-sample $x^{2}$ test, one-way analysis of variance, and binary logistic regression models were used for investigating group differences. Variables for analysis were age, gender, clinical assessments, on-scene time, priority levels, result of response, and temporal patterns.
\end{abstract}

Results: Of all included emergency ambulance assignments $(n=28,533), 59.9 \%$ involved older adults, of which $53.8 \%$ were women. The probability for older adults to receive the highest priority was decreased for both dispatch $(p<0.001$, odds ratio [OR] 0.63, 95\% confidence interval [CI] 0.59-0.66), and transport priorities $(p<0.001$, OR 0.74, $95 \% \mathrm{Cl} 0.68-0.80$ ). Older adults were more likely to receive dispatch priority levels 2 ( $p<0.001$, OR $1.48,95 \% \mathrm{Cl}$ $1.40-1.56)$, and $3(p<0.001, \mathrm{OR} 1.73,95 \% \mathrm{Cl} 1.46-2.06)$. The older adults were similarly more likely to receive transport priority level $3(p<0.001$, OR $1.40,95 \% \mathrm{Cl} 1.28-1.52)$ compared with adults. Age had a small but additive effect in relation to on-scene time $\left(p<0.001, R^{2}=0.01, F=53.82\right)$. Distinguishing initial clinical assessments for older adults were circulatory, respiratory, trauma, infection, and nonspecific assessments. Emergency ambulance assignments for older adults were more frequently occurring on Mondays $\left(p<0.001, x^{2}=232.56\right)$, and in the 08:0011:59 interval $\left(p<0.001, x^{2}=1224.08\right)$.

Conclusion: The issues of the lower priority level preponderance, and the decreased probability for receiving the highest priority warrant further attention in future research and clinical practice.

Keywords: Ambulance, Characteristics, Emergency medical services, Older adults

\footnotetext{
* Correspondence: anna.hjalmarsson@mdh.se

'School of Health, Care and Social Welfare, Mälardalen University, Eskilstuna Västerås, Sweden

Full list of author information is available at the end of the article
}

C The Author(s). 2020 Open Access This article is licensed under a Creative Commons Attribution 4.0 International License, which permits use, sharing, adaptation, distribution and reproduction in any medium or format, as long as you give appropriate credit to the original author(s) and the source, provide a link to the Creative Commons licence, and indicate if changes were made. The images or other third party material in this article are included in the article's Creative Commons licence, unless indicated otherwise in a credit line to the material. If material is not included in the article's Creative Commons licence and your intended use is not permitted by statutory regulation or exceeds the permitted use, you will need to obtain permission directly from the copyright holder. To view a copy of this licence, visit http://creativecommons.org/licenses/by/4.0/. The Creative Commons Public Domain Dedication waiver (http://creativecommons.org/publicdomain/zero/1.0/) applies to the data made available in this article, unless otherwise stated in a credit line to the data. 


\section{Background}

There is an ongoing shift in population demographics worldwide, from younger to older age [1]. Therefore, the World Health Organization strongly recommends that health care systems globally redesign their services to better fulfill older people's needs and to promote their independence [1]. Older age entails prevalence of cognitive and physical impairments, chronic medical conditions, and frailty, thus increasing the need for emergency ambulance care [2-6]. Currently, approximately 1.5 million people in Sweden are aged $>70$ years [7], a population that is estimated to rise by $25 \%$ over the next 15 years [8]. In addition, the population of the current 0.5 million people aged $>80$ years [7] is estimated to rise by $61 \%$ in the same period [8]. Life expectancy in Sweden is high compared with many other countries. A global ranking places Sweden 11th [9] with an average life expectancy of 84.7 years for women and 81.3 years for men [10]. By 2060, the life expectancies of Swedish women and men are estimated to reach 89.1 and 86.7 years respectively [11]. Due to targeted political governance, the vast majority of older adults live in their own private homes throughout life, only about 80,000 older adults live in nursing homes [12]. Hence, the emergency needs of the older adult population living at home will substantially impact future ambulance care.

The Swedish emergency medical services (EMS) providing emergency ambulance care are regulated by law, which states that high-quality care is to be provided to all, assuring safety, equality, and patient participation [13, 14]. Swedish EMS personnel are the frontline providers of this stated care and include primarily registered nurses with a bachelor's degree and specialist nurses with postgraduate education within, for example, prehospital, anesthetic, or intensive care (henceforth, registered and specialist nurses are referred to as RNs). The Swedish EMS RNs have an autonomous prehospital medical and caring responsibility, requiring specialist competence [15]. The context of prehospital emergency care is complex, and the RNs need to adjust to organizational requirements of rapid responses and available care options in relation to the patient's medical or personal needs, and safety [15]. The prehospital assessment is based on very limited background information, and entails considerations of risks versus benefits influenced by the EMS RN's competence, experience, organizational support, and guidelines [16, 17]. The EMS RNs carry out an initial clinical assessment of the patient's symptoms and emergency need on scene, to determine the adequate level of emergency care and transport priority if conveyance to hospital is deemed necessary. The options for level of care are limited in Sweden, and generally include conveyance to hospital or leaving the older adult at home. Older adults are challenging to clinically assess, often displaying low acuity conditions $[18,19]$ or atypical or masked symptoms due to conditions such as polypharmacy, dementia, or chronic diseases [20]. The prehospital assessment and the level of care provided, plays a paramount role for the health outcome of older adults.

Previous research focusing on older adults receiving ambulance care reported such assignments to be prolonged compared with those for younger adults [21], and that conveyance rates were high [5, 21]. An Australian study reporting temporal patterns of ambulance demand for community dwelling older adults, found that such calls peaked on Mondays around 11:00 and were more frequent in the Australian winter and spring [5]. A Swedish study of EMS assignments for older adults found that such adults were more frequently assessed as having nonspecific conditions, and that age and gender influenced the assessments [22].

Swedish EMS research targeting specific emergency needs of the increasing population of older adults living at home is however scarce. This study provides an understanding of prevalent emergency ambulance assignments for older adults living at home in Sweden. Since the Swedish EMS is a statutory welfare service, defined to be safe, equal, and of high quality for all, it is of likewise importance to describe potential inequalities between populations. Such knowledge would further enable interventions beneficial for older adults, in accordance with the legislative liability of the EMS. To identify characteristics representative of assignments for older adults, we performed a comparative analysis between older adults and the general adult population. Hence, the overall study aim was to describe characteristic patterns of dyadic staffed emergency ambulance assignments for older adults aged > 70 years compared with adults aged 18-69 years requiring emergency care at home. Age group differences in the following were investigated: age and gender frequency; result of response; priority levels; clinical assessments; on-scene time; and temporal patterns.

\section{Methods \\ Study design}

The present study had a descriptive 2-year range retrospective design. Registry data from the Swedish EMS in the region of Sörmland was analyzed, comprising all EMS assignments from January 2017 to December 2018. Ethical approval was obtained by the Swedish Ethical Review Authority (Dnr: 2019-02027), and access permission to anonymized registry data was provided by the manager of the EMS in the region.

\section{Study setting}

The region included in this study is one of 21 regions in Sweden. This medium-sized region (ca. $6000 \mathrm{~km}^{2}$ ) is situated southwest of Stockholm, and consists of nine municipalities covering rural and urban areas. The region 
has a population of approximately 300,000 inhabitants, with $85 \%$ of them living in urban areas [23]. Approximately $17 \%$ of the inhabitants are older adults aged $>70$ years, of which $54 \%$ are women [24]. The EMS of the region cover six ambulance stations, each located in one of the six largest municipalities. On weekdays, the EMS have at their disposal 16 daytime (08:00-18:00) emergency ambulance vehicle units and 11 nighttime (18:00-08:00) units. At weekends, 13 and 10 vehicles are available, respectively. Swedish EMS personnel mainly work in dyads, and besides RNs, emergency medical technicians (EMTs) mainly trained as assistant nurses are a common part of the team [25]. All dyadic staffed emergency ambulances in Sweden are considered advanced life support (ALS) units [15], and the RNs are licensed for drug administration [25]. Single responder ambulances have been implemented in the Swedish EMS, managed by one RN alone and not used for conveyance [26]. The Swedish EMS utilize the Rapid Emergency Triage and Treatment System (RETTS৫) as an instrument for triage [27]. EMS physicians mainly serve as medical advisors, and are not part of the ambulance team [25].

Three descending levels of emergency are used for prioritizing EMS assignments by the emergency medical communication centers (EMCC) receiving medical emergency calls: 1) life-threatening or possibly life-threatening; 2) not life-threatening, requiring advanced care and conveyance; and 3) not life-threatening, advanced care and conveyance required within a reasonable time [28]. Level 1 is a high priority level indicating unstable vital signs, and levels 2 and 3 are considered lower priority levels indicating stable vital signs.

Swedish health care is part of a welfare system financed by the regions through income taxes and government support. The cost for EMS responses is settled by the regions. In the region of the present study, ambulance responses are free of charge for citizens aged $0-19$ and $>85$ years and subsidized for other citizens (ca. $€ 37 / \mathrm{US} \$ 41$ per response).

\section{Study population}

The data comprise all assignments performed by the EMS $(N=75,088)$ in $2017-2018$. The final sample $(n=$ $28,533)$ for analysis represents primary dyadic staffed ALS emergency ambulance assignments for adults requiring emergency care at home, resulting in conveyance or nonconveyance, with entries made in clinical records for possible calculation of on-scene time (Fig. 1). In the present study, older adults are defined as those aged > 70 years, and adults as aged $18-69$ years. This age cutoff has been previously used in similar research [29].

\section{Variables for analysis}

A total of seven assignment variables were processed for analysis: age, gender, result of response, priority levels, on-scene time, clinical assessments, and temporal patterns. Age was analyzed as a continuous variable or stratified into two age groups: adults (18-69 years) and older adults (70-104 years). Age was additionally stratified into eight age groups for one-way analysis of variance, and for visual display of responses in relation to age $(18-29,30-39,40-49,50-59,60-69,70-79,80-89$, and $90-104$ years). The dichotomous age group variable is used as the main predictor in the logistic regression models.

Result of response is denoted as conveyance (transport to hospital) or nonconveyance (remain at home). The variable is used as outcome, and as predictor in other logistic regression models. Dispatch priority denotes the priority level assigned to the EMS response by the EMCC receiving the medical emergency call. Transport priority denotes the priority level assigned to the patient by the EMS RNs when conveyed to hospital. The three priority levels were dichotomized for binary logistic regression modeling: level $1 /$ level 2 or 3 , level $2 /$ level 1 or 3 , and level $3 /$ level 1 or 2 . The level $1 /$ level 2 or 3 variable is used as predictor in other logistic regression models.

The clinical assessments in the registry data encompassed 134 assessments entered by the EMS RNs. These assessments were clustered into 14 categories in accordance with the emergency signs and symptoms (ESS) grouping used by the EMS in the region [27]. Of the 14 categories, two were without any clinical assessment (transfer, other) and therefore presented as missing cases. For analysis using binary logistic regression, the assessments were dichotomized (assessment/all other assessments). The variable is used as outcome, and as predictor in other logistic regression models.

Ambulance on-scene time denotes the time in minutes spent in the home of the adults and older adults or in the ambulance on the scene, ranging from 1 to $235 \mathrm{~min}$. The variable was calculated by subtracting ambulance arrival time from departure time, in consensus with the registry manager of the EMS. The variable is used for one-way analysis of variance and as predictor in the logistic regression models.

Temporal patterns were categorized into three time periods: diurnal, weekly, and seasonal. The diurnal variable was further divided into two or six periods of time: 08:00-17:59 (daytime) and 18:00-07:59 (nighttime) in accordance with the EMS ambulance disposition, and in 4-h intervals: 00:00-03:59, 04:00-07:59, 08:00-11:59, 12: 00-15:59, 16:00-19:59, and 20:00-23:59. The weekly variables were stratified into two or seven time periods: weekdays (Monday-Friday) and weekend (SaturdaySunday), and each day of the week. The seasonal variable was stratified into four categories: winter (DecemberFebruary), spring (March-May), summer (June-August), 


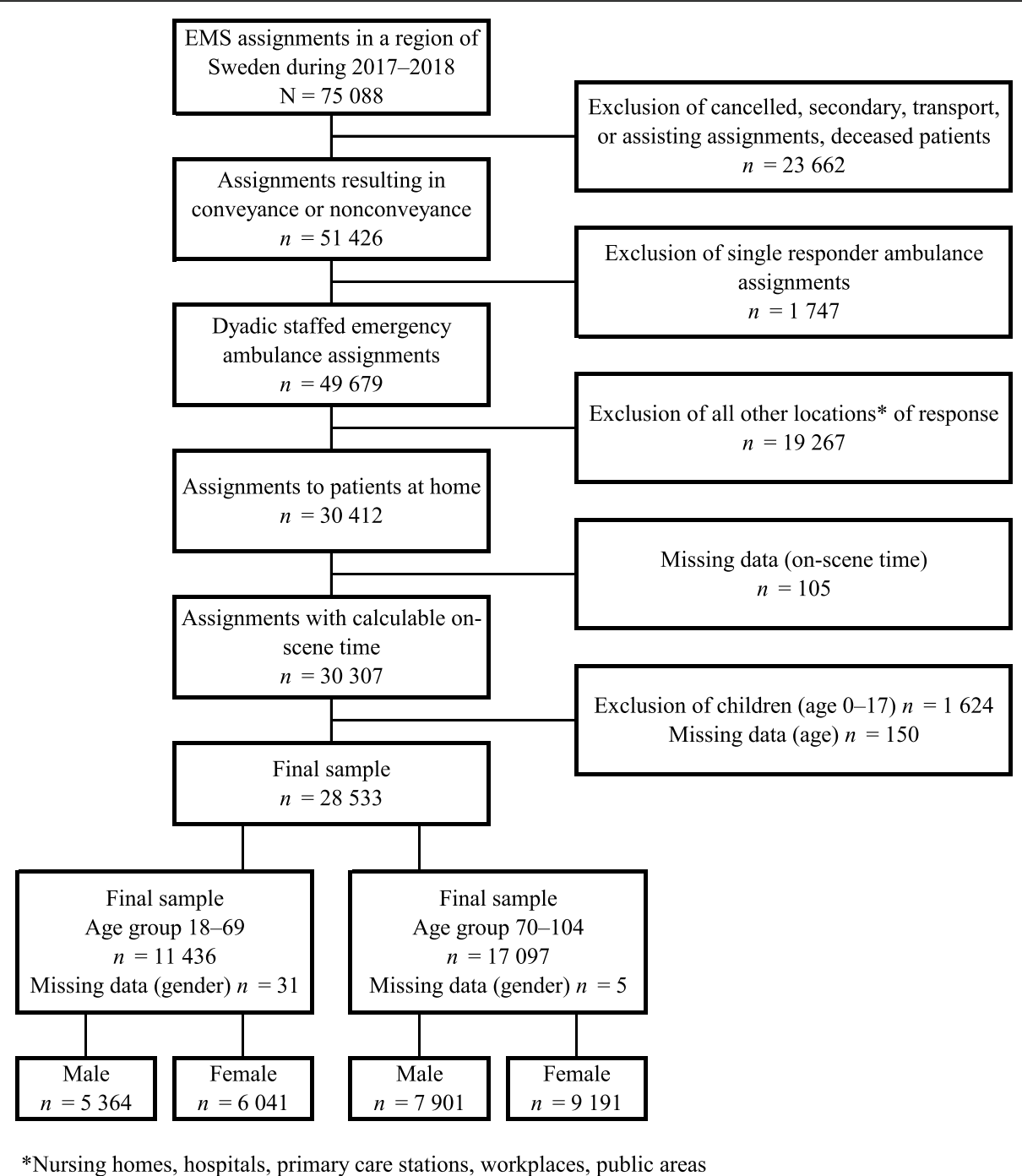

Fig. 1 Flow chart of final sample. The sample $(n=28,533)$ represents primary dyadic staffed emergency ambulance assignments for adults and older adults requiring emergency care at home, resulting in conveyance or nonconveyance

and autumn (September-November). The variable is used in one-sample $x^{2}$ test, and the dichotomous daytime/nighttime variable is used as predictor in the logistic regression models, referred to as time of day.

\section{Statistical analysis}

Descriptive statistics are presented using frequencies and percentages for categorical variables and using means and standard deviations for continuous variables. Nonparametric variable correlations were analyzed using one-sample $x^{2}$ test, and one-way analysis of variance was used for age and on-scene time correlations, with supplementary Scheffe's post hoc for between group multiple comparison. Binary logistic regression models were used to analyze the dichotomized outcome variables priority level, result of response, and initial clinical assessment. The chosen predictor variables were discussed among the researchers, and considered to be of importance for the outcome variables. A $p$-value < 0.05 was considered statistically significant. All analyses were performed using IBM SPSS Statistics (version 24.0; IBM SPSS, Armonk, NY, USA).

\section{Results}

Of the 28,533 included dyadic staffed emergency ambulance assignments to private homes in the region during 2017-2018, 17,097 (59.9\%) involved older adults aged > 70 years $($ mean $=81.3$, standard deviation $=7.0$, range $=$ $70-104$ years), of which $53.8 \%$ were women. In relation to age, there was a considerable increase in assignments for older adults aged 70-79 and 80-89 years (Fig. 2).

Older adults were more likely to be conveyed to hospital compared to the adult population $(p<.001$, adjusted odds ratio [adjOR] 1.79, 95\% confidence interval 


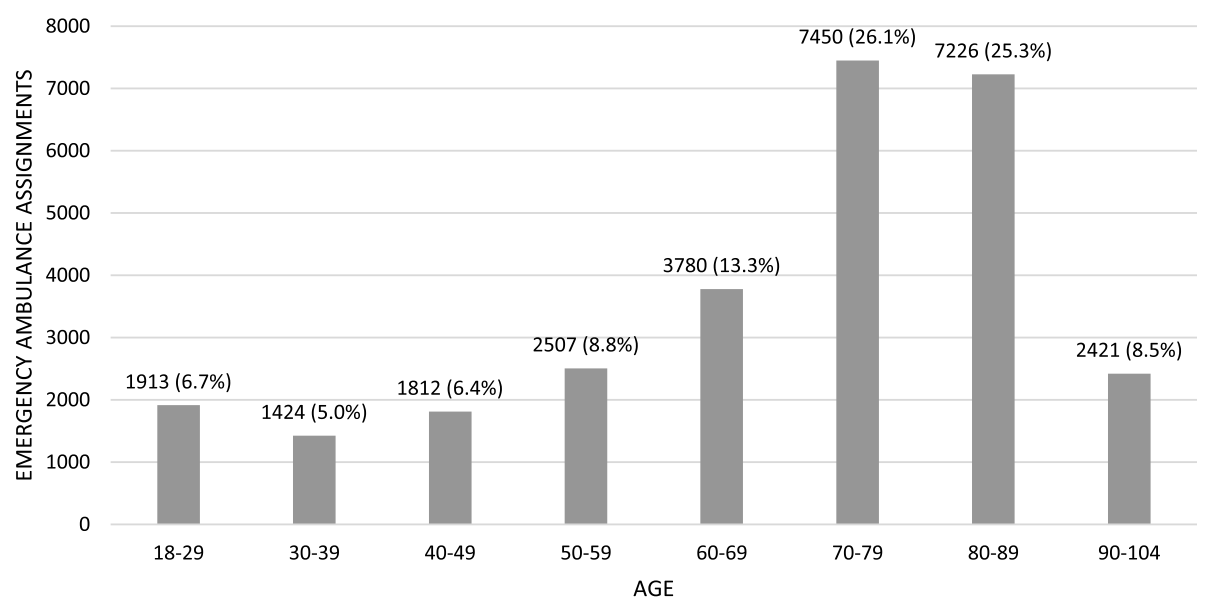

Fig. 2 Dyadic staffed emergency ambulance assignments to private homes in the region of Sörmland in Sweden 2017-2018, stratified by age groups

[CI] 1.33-2.40) (Table 2), the conveyance rate being $89.4 \%$ within the older adult age group compared with $82.6 \%$ in the adult age group (Table 1). In the adult population, $46.0 \%$ received the highest priority, in contrast to only $37.3 \%$ in the older adult group (Table 1 ). The likelihood for older adults to receive the highest priority level was reduced for both dispatch $(p<.001$, adjOR $0.63,95 \%$ CI $0.59-0.66$ ), and transport priorities $(p<.001$, adjOR $0.74,95 \%$ CI $0.68-0.80)$ (Table 2$)$. The probability for receiving a dispatch priority level 2 $(p<.001$, adjOR $1.48,95 \%$ CI $1.40-1.56)$ or $3(p<.001$, adjOR 1.73, 95\% CI 1.46-2.06) was increased for the older adults (Table 2), constituting 59.9 and $2.7 \%$ of the older adults compared with 52.1 and $1.9 \%$ in the adult population (Table 1). The older adult group were similarly more likely to receive a transport priority level 3 $(p<.001$, adjOR $1.40,95 \%$ CI 1.28-1.52) compared with the adults (Table 2). The proportion of transport priority level 2 were similar in both age groups, $72.9 \%$ of the adults and $73.1 \%$ of the older adults received priority level 2 , and there was no difference in odds ratio (Table 2).

Circulatory, respiratory, trauma, infection, and nonspecific assessments were predominant in the older adult age group, and the probability for all assessments but circulatory and trauma were more than doubled (Table 3). Eye, ear, nose and throat assessments had a similar increased likelihood, but represented only $1.1 \%$ of the assessments within the age group.

Figure 3 displays the impact of age on emergency ambulance on-scene time. Age had a small although additive effect in relation to on-scene time $\left(p<0.001, \mathrm{R}^{2}=\right.$ $0.01, \mathrm{~F}=53.82$ ). The $p$-values displayed in Fig. 3 , indicate age groups with significantly longer on-scene time.

Age group differences were found in all temporal variables (Table 4). Compared to the adult population, emergency ambulance assignments for older adults were
Table 1 Characteristics of emergency ambulance assignments for adults and older adults at home in Sweden

\begin{tabular}{lll}
\hline Age group & $\begin{array}{l}\text { Adults (18-69) } \\
\boldsymbol{n}=\mathbf{1 1 , 4 3 6}\end{array}$ & $\begin{array}{l}\text { Older adults (70-104) } \\
\boldsymbol{n}=\mathbf{1 7 , 0 9 7}\end{array}$ \\
\hline Age (years) & & \\
Mean (SD) & $48.9(15.3)$ & $81.3(7.0)$ \\
Male (SD) & $50.5(14.9)$ & $80.5(6.6)$ \\
Female (SD) & $47.5(15.5)$ & $81.9(7.3)$ \\
Median & 52 & 81 \\
Male & 54 & 80 \\
Female & 49 & 82 \\
Gender $n$ (\% within group) & & \\
Male & $5364(47.0)$ & $7901(46.2)$ \\
Female & $6041(53.0)$ & $9191(53.8)$ \\
Result of response $n$ (\% within group) & $15,279(89.4)$ \\
Conveyance & $9443(82.6)$ & $1818(10.6)$ \\
Non-conveyance & $1993(17.4)$ & \\
Priority level $n$ (\% within group) & \\
Dispatch priority level 1 & $5256(46.0)$ & $6382(37.3)$ \\
Dispatch priority level 2 & $5961(52.1)$ & $10,247(59.9)$ \\
Dispatch priority level 3 & $219(1.9)$ & $468(2.7)$ \\
Transport priority level 1 & $1391(14.6)$ & $2045(13.3)$ \\
Transport priority level 2 & $6956(72.9)$ & $11,239(73.1)$ \\
Transport priority level 3 & $1199(12.6)$ & $2098(13.6)$ \\
\hline
\end{tabular}

${ }^{a}$ Missing cases: gender; adults 31, older adults 5

${ }^{b}$ Patients receiving transport priority without recorded entries of conveyance; adults 103 , older adults 103

Descriptive statistics presented for age, gender, result of response, and priority level variables. Percentage in brackets display within group proportion 
Table 2 Priority levels and result of response for older adults at home in Sweden

\begin{tabular}{|c|c|c|c|c|c|c|}
\hline \multicolumn{4}{|c|}{$\begin{array}{l}\text { Adults }(18-69) n=11,436 \\
\text { Older adults }(70-104) n=17,097\end{array}$} & \multirow{2}{*}{$\begin{array}{l}\text { Unadjusted } \\
\text { OR }(95 \% \mathrm{Cl})\end{array}$} & \multirow[b]{2}{*}{$p$} & \multirow{2}{*}{$\begin{array}{l}\text { Adjusted } \\
\text { OR }(95 \% \mathrm{Cl})\end{array}$} \\
\hline Priority level & Age group & (\% within group) & $p$ & & & \\
\hline \multirow[t]{2}{*}{ Dispatch Priority level 1} & Adults & $(46.0)$ & & Ref & & Ref \\
\hline & Older adults & $(37.3)$ & $<.001$ & $0.70(0.67-0.74)$ & $<.001$ & $0.63(0.59-0.66)$ \\
\hline \multirow[t]{2}{*}{ Dispatch priority level 2} & Adults & $(52.1)$ & & & & \\
\hline & Older adults & $(59.9)$ & $<.001$ & $1.37(1.31-1.44)$ & $<.001$ & $1.48(1.40-1.56)$ \\
\hline \multirow[t]{2}{*}{ Dispatch priority level 3} & Adults & (1.9) & & & & \\
\hline & Older adults & $(2.7)$ & $<.001$ & $1.44(1.23-1.70)$ & $<.001$ & $1.73(1.46-2.06)$ \\
\hline \multirow[t]{2}{*}{ Transport priority level 1} & Adults & $(14.6)$ & & & & \\
\hline & Older adults & (13.3) & .005 & $0.90(0.84-0.97)$ & $<.001$ & $0.74(0.68-0.80)$ \\
\hline \multirow[t]{2}{*}{ Transport priority level 2} & Adults & $(72.9)$ & & & & \\
\hline & Older adults & (73.1) & .740 & $1.01(0.95-1.07)$ & .820 & $0.99(0.93-1.06)$ \\
\hline \multirow[t]{2}{*}{ Transport priority level 3} & Adults & $(12.6)$ & & & & \\
\hline & Older adults & (13.6) & .016 & $1.10(1.02-1.19)$ & $<.001$ & $1.40(1.28-1.52)$ \\
\hline \multicolumn{7}{|l|}{ Result of response } \\
\hline \multirow[t]{2}{*}{ Conveyance } & Adults & $(82.6)$ & & & & \\
\hline & Older adults & (89.4) & $<.001$ & $1.77(1.66-1.90)$ & $<.001$ & $1.79(1.33-2.40)$ \\
\hline
\end{tabular}

Binary logistic regression models for priority level and result of response variables presented as unadjusted, and adjusted odds ratios (OR) with $95 \%$ confidence interval (Cl). Independent variables adjusted for in the priority level models are gender, initial clinical assessment, on-scene time, result of response and time of day. Independent variables adjusted for in the result of response model are gender, initial clinical assessment, on-scene time, priority level and time of day. Percentage in brackets displays proportion within age group. Significant adjusted odds ratios differentiating the older adult group are highlighted in bold text

more frequent during daytime, and in the 08:00-11.59 interval (Fig. 4). An older adult preponderance was additionally found on weekdays, on Mondays (Fig. 4), and in the winter.

The differences were similarly found in a one-sample $x^{2}$ test of within group variations (not shown in table). Assignments for adults were increasing in the afternoon, being most frequent in the evening between 20:00-23.59 $\left(p<0.001, x^{2}=465.32\right)$. Assignments within the older adult group were found less than expected in all intervals apart from 08:00-11.59, 12:00-15.59, and 16:00-19.59, the greatest difference found in the forenoon $(p<0.001$, $\left.X^{2}=2839.96\right)$. Assignments for the older adults were found more than expected during daytime $\left(p<0.001, x^{2}=\right.$ 419.16) and in weekdays $\left(p<0.001, x^{2}=3519.39\right)$, compared to the adults that were found more than expected during nighttime $\left(p<0.001, \chi^{2}=139.27\right)$, and in the weekends $\left(p<0.001, \quad X^{2}=1811.88\right)$. Assignments for older adults were found more than expected in all days of the week, apart from Thursdays, Saturdays and Sundays, and most frequent on Mondays $\left(p<0.001, x^{2}=29.17\right)$. In contrast, assignments for the adult population were less than expected all week apart from Saturdays and Sundays, most frequently occurring on Sundays $\left(p=0.008, \chi^{2}=17.32\right)$. In the seasonal variable, assignments for the older adults were more frequent in the winter, spring, and summer, being most frequent in the winter $\left(p=0.005, \chi^{2}=12.859\right)$.
Assignments for the adult population were most frequent in the summer $\left(p<0.001, x^{2}=36.30\right)$.

\section{Discussion}

The aim of the present study was to describe characteristic patterns of dyadic staffed emergency ambulance assignments for older adults aged $>70$ years compared with adults aged 18-69years requiring emergency care at home. The main finding was the preponderance of lower priority levels in the older adult group, in addition to a decreased probability of them receiving the highest priority compared with the adult age group. The reason for this finding might be indicative of the complexity and challenges related to assessing the emergency needs of older adults. Masked symptoms due to polypharmacy, cognitive decline or even natural bodily changes clouds the clinical picture, and make critical conditions hard to detect [20]. In addition, underlying societal tendencies of ageism might be a contributing factor, which are currently being addressed by the World Health Organization to increase the knowledge and competence of health care providers worldwide [1]. Furthermore, the RETTS $\odot$, based on vital signs and cutoff points, has been criticized for not being able to differentiate between stable and unstable patients [30]. Swedish EMS RNs report feeling alone in the assessment process, being uncertain about making the right decision, in fear of harming the patient [31]. Another 
Table 3 Initial clinical assessments for adults and older adults at home in a region of Sweden

\begin{tabular}{|c|c|c|c|c|c|c|}
\hline \multicolumn{4}{|l|}{$\begin{array}{l}\text { Adults }(18-69) n=11,436 \\
\text { Older adults }(70-104) n=17,097\end{array}$} & \multirow{2}{*}{$\begin{array}{l}\text { Unadjusted } \\
\text { OR }(95 \% \mathrm{Cl})\end{array}$} & \multirow[b]{2}{*}{$p$} & \multirow{2}{*}{$\begin{array}{l}\text { Adjusted } \\
\text { OR }(95 \% \mathrm{Cl})\end{array}$} \\
\hline Initial clinical assessment ${ }^{\mathrm{a}}$ & Age group & $n(\%)$ & $p$ & & & \\
\hline \multirow{2}{*}{$\begin{array}{l}\text { Circulatory } \\
\text { (e.g. chest pain, cardiac arrest/dysrhythmia, hypertension) }\end{array}$} & Adults & $1997(17.5)$ & .240 & Ref & & Ref \\
\hline & Older adults & $2894(16.9)$ & & $0.96(0.91-1.03)$ & .023 & $1.09(1.01-1.17)$ \\
\hline \multirow[t]{2}{*}{ Eye, ear, nose, throat (e.g. bleeding, pain, foreign body) } & Adults & $64(0.6)$ & & & & \\
\hline & Older adults & $190(1.1)$ & $<.001$ & $2.00(1.50-2.65)$ & $<.001$ & $2.60(1.86-3.65)$ \\
\hline \multirow{2}{*}{$\begin{array}{l}\text { Genital } \\
\text { (gynecology, urology) }\end{array}$} & Adults & $194(1.7)$ & & & & \\
\hline & Older adults & $292(1.7)$ & .941 & $1.01(0.84-1.21)$ & 302 & $1.11(0.91-1.36)$ \\
\hline \multirow[t]{2}{*}{ Infection } & Adults & $581(5.1)$ & & & & \\
\hline & Older adults & $1732(10.1)$ & $<.001$ & $2.11(1.91-2.32)$ & $<.001$ & $2.05(1.84-2.27)$ \\
\hline \multirow{2}{*}{$\begin{array}{l}\text { Medical } \\
\text { (e.g. anemia, diabetic symptoms, Addison's disease, } \\
\text { immune deficiency) }\end{array}$} & Adults & 1109 (9.7) & & & & \\
\hline & Older adults & $1189(7.0)$ & $<.001$ & $0.70(0.64-0.76)$ & $<.001$ & $0.63(0.57-0.70)$ \\
\hline \multirow{2}{*}{$\begin{array}{l}\text { Neurology } \\
\text { (e.g. stroke, headache, seizure, loss of consciousness, } \\
\text { dizziness) }\end{array}$} & Adults & $1952(17.1)$ & & & & \\
\hline & Older adults & 2727 (16.0) & .012 & $0.92(0.87-0.98)$ & .120 & $0.95(0.88-1.01)$ \\
\hline \multirow[t]{2}{*}{ Nonspecific } & Adults & $216(1.9)$ & & & & \\
\hline & Older adults & 673 (3.9) & $<.001$ & $2.13(1.83-2.49)$ & $<.001$ & $2.08(1.73-2.50)$ \\
\hline \multirow{2}{*}{$\begin{array}{l}\text { Orthopedic } \\
\text { (e.g. musculoskeletal pain) }\end{array}$} & Adults & $585(5.1)$ & & & & \\
\hline & Older adults & $824(4.8)$ & .255 & $0.94(0.84-1.05)$ & $<.001$ & $0.71(0.63-0.81)$ \\
\hline \multirow{2}{*}{$\begin{array}{l}\text { Psychiatric } \\
\text { (e.g. psychiatric disorders, suicidality, anxiety, drug abuse) }\end{array}$} & Adults & $520(4.5)$ & & & & \\
\hline & Older adults & $194(1.1)$ & $<.001$ & $0.24(0.20-0.29)$ & $<.001$ & $0.21(0.17-0.26)$ \\
\hline \multirow{2}{*}{$\begin{array}{l}\text { Respiratory } \\
\text { (e.g. respiratory distress, dyspnea, hyperventilation) }\end{array}$} & Adults & 731 (6.4) & & & & \\
\hline & Older adults & $2232(13.1)$ & $<.001$ & $2.20(2.02-2.40)$ & $<.001$ & $2.41(2.19-2.66)$ \\
\hline \multirow{2}{*}{$\begin{array}{l}\text { Surgical } \\
\text { (e.g. gastrointestinal hemorrhage, abdominal pain, } \\
\text { nausea/vomiting) }\end{array}$} & Adults & $1740(15.2)$ & & & & \\
\hline & Older adults & $1654(9.7)$ & $<.001$ & $0.60(0.55-0.64)$ & $<.001$ & $0.58(0.54-0.68)$ \\
\hline \multirow{2}{*}{$\begin{array}{l}\text { Trauma } \\
\text { (physical injury) }\end{array}$} & Adults & $1075(9.4)$ & & & & \\
\hline & Older adults & 1998 (11.7) & $<.001$ & $1.28(1.18-1.38)$ & .023 & $1.10(1.01-1.20)$ \\
\hline
\end{tabular}

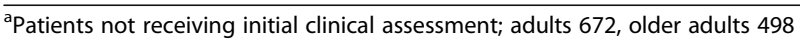

Binary logistic regression models for each assessment presented as unadjusted, and adjusted odds ratios (OR) with $95 \%$ confidence interval (CI). Independent variables adjusted for in the models are gender, on-scene time, priority level, result of response and time of day. Adjusted odds ratios characterizing initial clinical assessments for older adults are highlighted in bold text. The proportion of adults and older adults receiving the assessment within the age group is displayed as $n$ (\%)

Swedish study similarly concluded that decisions of nonconveyance were difficult and involved a great responsibility [32]. The lack of organizational support, and the risk of being held liable if the wrong decision is made are factors influencing EMS personnel's decisions [16, 33]. However, a recent review by Yeung et al. [34] found decisions of nonconveyance to be relatively safe for patients. Further attention needs to be paid to why older adults receive lower priorities.

In the present study, $89.4 \%$ of the older adults were conveyed to hospital. Conveyance is however not always a suitable option. A major reason for conveyance is the lack of options that results in inadequate transportations to overcrowded emergency departments (EDs) [18, 35]. Frail older adults, being physically intolerant and vulnerable to acute illnesses, do not adapt well to the busy environment at the ED [36]. Moreover, older adults are more likely to have longer waiting times in an ED than younger adults [37, 38]. ED admittance also implies an increased risk for missed diagnoses, delirium, infection [39], pressure ulcers [40], and defaulted care [41-43]. Conveyance of older adults assessed as having low or no acuity might however also be representative of patient participation, the EMS personnel being responsive to the patient's requests and preferences when deciding about care $[17,44]$. In perceived emergency situations, an individual is authorized to call for an ambulance, even for low acuity conditions [45].

Similar to the present case, the problem of a lack of options apart from ED conveyance exists in many countries. A Japanese study [18] suggested focusing on primary care and expanding primary clinic office hours. An Australian study evaluating the establishment of an "acute geriatric outreach service" reported positive results regarding patient 


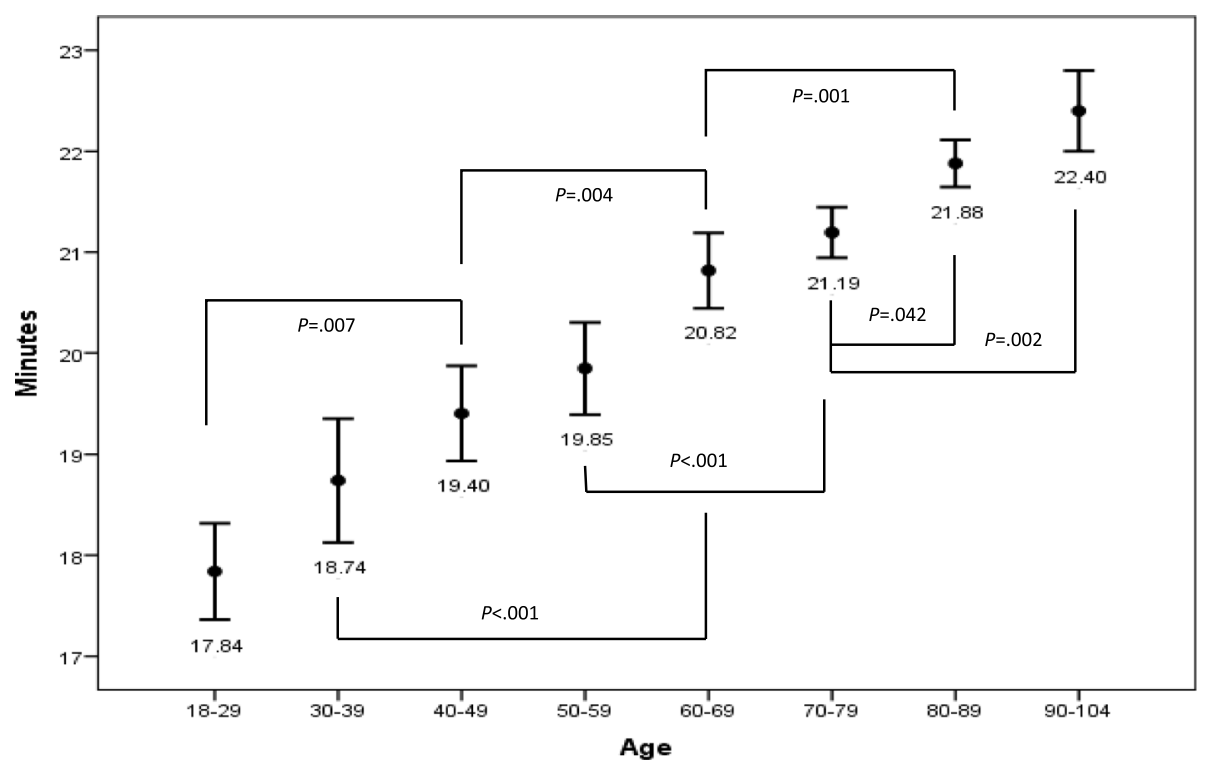

Fig. 3 Mean and 95\% confidence interval for emergency ambulance on-scene time using one-way analysis of variance, and Scheffe's post hoc. Age groups having significant longer on-scene time are displayed with $p$-values in the figure

safety [46]. In Sweden, older adults expressed satisfaction when offered admittance to a geriatric ward instead of traditional conveyance to EDs when possible, due to previous negative experiences of ED admittance [41]. Shared decision-making was similarly pointed out as beneficial for improving EMS care for older adults in the US [47]. In addition, a possibility for the EMS personnel to consult a physician decreased unnecessary conveyance for low acuity patients in Sweden [48].

In Sweden, mortality is high due to circulatory diseases such as heart failure [11], with the cause of death primarily being related to prior morbidity. The predominance of circulatory clinical assessments in both age groups, provides further support for this finding, implying a future substantial impact on the EMS. Respiratory as well as trauma and nonspecific clinical assessments are reported as being distinctive to older adults worldwide $[5,18,49,50]$. In the present study, psychiatric assessments were highly associated with the adult age group. This finding is in accordance with Vloet et al. [51], who related behavioral, mental, and neurodevelopmental disorders more frequently to younger nonconveyed patients. However, it can be speculated that psychiatric conditions in older adults become more obscure, meaning that more salient chronic physical conditions are easier to assess. A US study of older adults (aged 55-93 years) found that chronic conditions such as heart or respiratory diseases relate to higher self-reports of depressive symptoms [52]. A recent review focusing on suicidal behavior in older adults concluded that functional disabilities and somatic illness were contributing factors [53].
Concerning the extended on-scene time, research indicates that the clinical complexity of older adults prolongs the overall EMS response time [35, 54]. Harmsen et al. [55] related prolonged on-scene time to more comprehensive care, and additionally suggested a future emphasis on prehospital emergency care, rather than focusing on rapid transportation to EDs. The clinical implications of our findings require further investigation. The actual difference in on-scene time between the youngest and oldest adult groups of patients was around $4.5 \mathrm{~min}$. This finding raises the question whether it is representative of more comprehensive care, or merely a representation of cognitive and functional impairments of older adults prolonging the on-scene time.

The present study found that emergency ambulance assignments for older adults at home were more frequently occurring on Mondays and in the 08:00-11:59 time interval, in accordance with Australian studies [5, 56]. The frequency of assignments on Mondays might be related to home care visits. Fewer visits on the weekends, as well as a greater number of temporary personnel, might prevent the detection of emerging acuity needs. Another reason for this finding may be knowledge about less resources being available on the weekends, making waiting until Monday an option to optimize care. More research is necessary to elucidate the causes underlying this pattern.

\section{Limitations}

Although the relatively large population used for analysis in the present study implies greater statistical power and trustworthiness, some limitations should be noted. The data processed for analysis are dependent on the accuracy 
Table 4 Temporal patterns of emergency ambulance assignments for adults and older adults at home in Sweden

\begin{tabular}{|c|c|c|c|c|}
\hline Age group & $\begin{array}{l}\text { Adults (18-69) } \\
n=11,436\end{array}$ & $\begin{array}{l}\text { Older adults (70-104) } \\
n=17,097\end{array}$ & $p$ & $x^{2}$ \\
\hline \multicolumn{5}{|l|}{$\begin{array}{l}\text { Diurnal patterns } \\
n \text { (\% within group) }\end{array}$} \\
\hline 00:00-03.59 & $1661(14.5)$ & $1547(9.0)$ & .044 & 4.05 \\
\hline 04:00-07.59 & $1182(10.3)$ & $1882(11.0)$ & $<.001$ & 159.92 \\
\hline 08:00-11.59 & $2074(18.1)$ & $5021(29.4)$ & $<.001$ & 1224.08 \\
\hline 12:00-15.59 & $2002(17.5)$ & $3480(20.4)$ & $<.001$ & 398.48 \\
\hline $16: 00-19.59$ & $2167(18.9)$ & $2904(17.0)$ & $<.001$ & 107.11 \\
\hline 20:00-23.59 & $2350(20.5)$ & $2263(13.2)$ & .200 & 1.64 \\
\hline 08:00-17.59 (daytime) & $5087(44.5)$ & $9887(57.8)$ & $<.001$ & 1538.67 \\
\hline 18:00-07.59 (nighttime) & $6349(55.5)$ & $7210(42.2)$ & $<.001$ & 54.67 \\
\hline \multicolumn{5}{|l|}{$\begin{array}{l}\text { Weekly patterns } \\
n \text { (\% within group) }\end{array}$} \\
\hline Monday & $1631(14.3)$ & $2626(15.4)$ & $<.001$ & 232.56 \\
\hline Tuesday & $1629(14.2)$ & $2483(14.5)$ & $<.001$ & 177.36 \\
\hline Wednesday & $1580(13.8)$ & $2455(14.4)$ & $<.001$ & 189.75 \\
\hline Thursday & 1579 (13.8) & $2390(14.0)$ & $<.001$ & 165.72 \\
\hline Friday & $1575(13.8)$ & $2473(14.5)$ & $<.001$ & 199.21 \\
\hline Saturday & $1678(14.7)$ & $2268(13.3)$ & $<.001$ & 88.22 \\
\hline Sunday & $1764(15.4)$ & $2382(13.9)$ & $<.001$ & 97.71 \\
\hline Weekday & 7994 (69.9) & $12,427(72.7)$ & $<.001$ & 962.32 \\
\hline Weekend & $3442(30.1)$ & $4670(27.3)$ & $<.001$ & 185.90 \\
\hline \multicolumn{5}{|l|}{$\begin{array}{l}\text { Seasonal patterns } \\
n \text { (\% within group) }\end{array}$} \\
\hline Winter (Dec-Feb) & $2845(24.9)$ & $4428(25.9)$ & $<.001$ & 344.55 \\
\hline Spring (Mars-May) & $2860(25.0)$ & $4284(25.1)$ & $<.001$ & 283.84 \\
\hline Summer (June-Aug) & $3093(27.0)$ & $4287(25.1)$ & $<.001$ & 193.18 \\
\hline Autumn (Sep-Nov) & $2638(23.1)$ & $4098(24.0)$ & $<.001$ & 316.45 \\
\hline
\end{tabular}

One-sample $x^{2}$ test investigating age group proportion in relation to number of assignments. Percentage in brackets display within group proportion. The $x^{2}$ values highlighted in bold text are the variables displaying the highest differences between the age groups

of the medical records entered by the EMS RNs. Some relevant data might therefore have been missed due to some inconsistencies in medical records. Because all registry data were anonymized, the possibility of recognizing repeated ambulance transports of the same individual was excluded. It was also not possible to cross-reference community records to identify the number of older adults requiring ambulance care who also utilized home care service, which would have strengthened this study. Another limitation is the lack of causality of the frequent level 2 priorities. This will be further explored in upcoming studies, based on interviews with EMS personnel and older adults.

Since the initial clinical assessment is primarily based on symptoms and vital signs, the assessment might not be consonant with the final ED diagnose. The potential divergence might result in inaccurate clinical data.
However, the assessments are anchored in the everyday reality of EMS RNs, and are the results of existing prerequisites, limitations, and competence. Another limitation concerns the evaluation of the logistic regression analysis, and the models' goodness of fit. In large datasets, the Hosmer-Lemeshow statistics displays deficits. However, the large sample size per se and the robustness of binary logistics might verify the models. Finally, the results of the present study might not be generalizable to other countries, populations, or age groups, although the use of a relatively large sample from the general population allows for broad generalizability to similar contexts.

\section{Conclusion}

Emergency ambulance assignments for older adults at home in a region of Sweden were characterized by a 


\section{DIURNAL VARIATION}

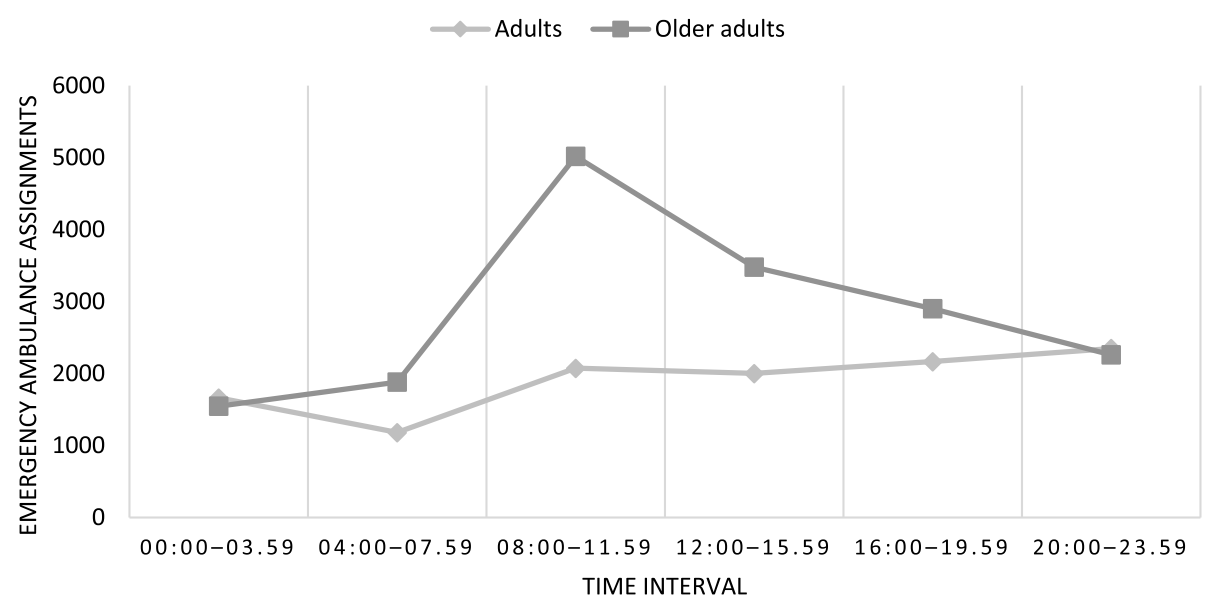

\section{WEEKLY VARIATION}

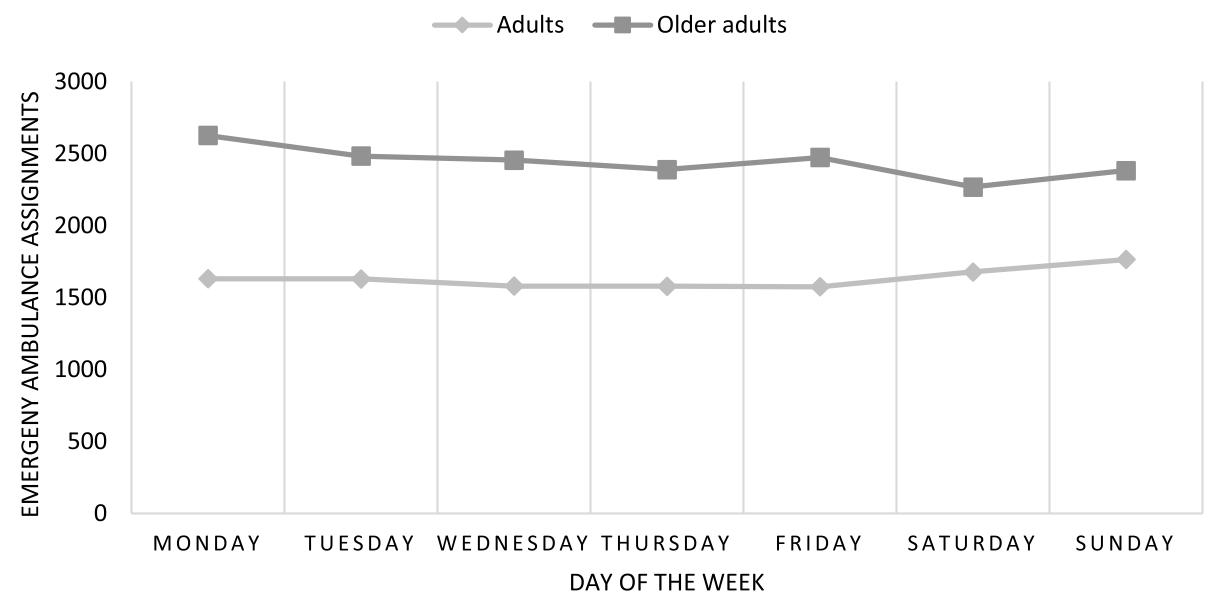

Fig. 4 Temporal patterns of emergency ambulance assignments for adults and older adults at home, in the region of Sörmland in Sweden 2017-2018

lower priority level preponderance, and a decreased probability for receiving the highest priority. Older adults were more likely to be conveyed, and differentiating initial clinical assessments were circulatory, respiratory, trauma, infection, and nonspecific assessments. Age had an additive effect in relation to on-scene time, and assignments for older adults at home were more frequently occurring during weekdays, on Mondays, and in the 08:00-11:59 interval. Considering the projected increase in the older adult population, the identified patterns may be of use in EMS resource allocation. Health care policy makers need to acknowledge the complex reality of the context, and design adequate and flexible levels of emergency care beneficial to older adults. The issue of the identified priority level divergence warrant further attention in future research, education and clinical practice.
Abbreviations

adjOR: Adjusted odds ratio; ALS: Advanced life support; Cl: Confidence interval; ED: Emergency department; EMCC: Emergency medical communication center; EMS: Emergency medical services; EMT: Emergency medical technician; OR: Odds ratio; RETTS: Rapid emergency triage and treatment system; RN: Registered nurse

\section{Acknowledgements}

We wish to thank Patric Bränderson at the Department of Ambulance Services, Region Sörmland, for his excellent support in providing access to registry data.

\section{Authors' contributions}

Study design ( $\mathrm{AH}, \mathrm{MH}, \mathrm{MA}, \mathrm{GO}, \mathrm{BK})$. Data collection $(\mathrm{AH}, \mathrm{MH})$. Data-analysis (AH, KN, BK). Manuscript preparation (AH, MH, MA, GÖ, KN, BK). All authors read and approved the final manuscript.

\section{Funding}

There was no funding body involved. Open Access funding provided by Malardalen Hogskola. 


\section{Availability of data and materials}

The datasets used and/or analyzed during the current study are available from the corresponding author on reasonable request.

\section{Ethics approval and consent to participate}

Ethical approval was obtained by the Swedish Ethical Review Authority (Dnr: 2019-02027), and access permission to anonymized registry data was provided by the manager of the EMS of the region.

\section{Consent for publication}

Not applicable.

\section{Competing interests}

The authors declare that they have no competing interests.

\section{Author details}

'School of Health, Care and Social Welfare, Mälardalen University, Eskilstuna Västerås, Sweden. ${ }^{2}$ Faculty of Health and Life Sciences, Linneaus University, Växjö, Sweden. ${ }^{3}$ Centre for Clinical Research Sörmland, Uppsala University, Eskilstuna, Sweden. ${ }^{4}$ Department of Ambulance Service, Region Sörmland, Eskilstuna, Sweden. ${ }^{5}$ Centre for Clinical Research Västerås, Uppsala University, Västmanland County Hospital, Västerås, Sweden.

\section{Received: 2 June 2020 Accepted: 16 November 2020}

\section{Published online: 02 December 2020}

\section{References}

1. World Health Organization. World report on ageing and health 2015: https://www.who.int/ageing/events/world-report-2015-launch/en/. Accessed 30 Mar 2020.

2. Platts-Mills TF, Leacock B, Cabanas JG, Shofer FS, McLean SA. Emergency medical services use by the elderly: analysis of a statewide database. Prehosp Emerg Care. 2010;14(3):329-33. https://doi.org/10.3109/10903127. 2010.481759

3. Jones CMC, Wasserman EB, Li T, Amidon A, Abbott M, Shah MN. The effect of older age on EMS use for transportation to an emergency department. Prehosp Disaster Med. 2017;32(3):261-8. https://doi.org/10.1017/ S1049023X17000036.

4. Dwyer R, Gabbe B, Tran TD, Smith K, Lowthian JA. Patterns of emergency ambulance use, 2009-13: a comparison of older people living in residential aged care facilities and the community. Age Ageing. 2018;47(4):615-9. https://doi.org/10.1093/ageing/afy056.

5. Cantwell K, Morgans A, Smith K, Livingston M, Dietze P. Differences in emergency ambulance demand between older adults living in residential aged care facilities and those living in the community in Melbourne, Australia. Australas J Ageing. 2017;36(3):212-21. https://doi.org/10.1111/ajag. 12413.

6. Evans CS, Platts-Mills TF, Fernandez AR, Grover JM, Cabanas JG, Patel MD, et al. Repeated emergency medical services use by older adults: analysis of a comprehensive statewide database. Ann Emerg Med. 2017;70(4):506-515. e503. https://doi.org/10.1016/j.annemergmed.2017.03.058.

7. Statistics Sweden. Population by age and sex: http://www.statistikdatabasen scb.se/pxweb/sv/ssd/START_BE_BE0101_BE0101A/BefolkningR1860/. Accessed 23 Mar 2020.

8. Statistics Sweden. Population by region of birth, age and sex. Year 20192120: http://www.statistikdatabasen.scb.se/pxweb/sv/ssd/START_BE_BE04 01_BE0401A/BefolkprognRevN/. Accessed 30 Mar 2020.

9. Infoplease. Life expectancy for countries; 2020. https://www.infoplease. $\mathrm{com} /$ world/health-and-social-statistics/life-expectancy-countries. Accessed 23 Mar 2020

10. Statistics Sweden. Medellivslängden i Sverige [life expectancy in Sweden]; 2020. https://www.scb.se/hitta-statistik/sverige-i-siffror/manniskorna-isverige/medellivslangd-i-sverige/. Accessed 17 Apr 2020.

11. Statistics Sweden. Hög medellivslängd i Sverige [high life expectancy in Sweden]; 2017. https:/www.scb.se/hitta-statistik/artiklar/2017/Hogmedellivslangd-i-Sverige/. Accessed 30 Mar 2020.

12. Swedish National Board of Health and Welfare. Statistik om socialtjänstinsatser till äldre [statistics about social services to older adults]; 2018. https:/www.socialstyrelsen.se/globalassets/sharepoint-dokument/ artikelkatalog/statistik/2019-5-7.pdf. Accessed 04 Mar 2020.
13. SFS 2017:30. Hälso- och sjukvårdslagen [the health and medical services care act]. 2017. Stockholm: Socialdepartementet [Ministry of health and social affairs].

14. SFS 2014:821. Patientlagen [the patient safety act]. 2014. Stockholm: Socialdepartementet [Ministry of health and social affairs].

15. Suserud BO, Lundberg L, editors. Prehospital akutsjukvård [Prehospital emergency care]. 2nd ed. Stockholm: Liber; 2016.

16. Ebben RHA, Vloet LCM, Speijers RF, Tönjes NW, Loef J, Pelgrim T, et al. A patient-safety and professional perspective on non-conveyance in ambulance care: a systematic review. Scand I Trauma Resusc Emerg Med. 2017;25(1):71. https://doi.org/10.1186/s13049-017-0409-6.

17. Jones CMC, Cushman JT, Lerner EB, Fisher SG, Seplaki CL, Veazie PJ, et al. Prehospital trauma triage decision-making: a model of what happens between the 9-1-1 call and the hospital. Prehosp Emerg Care. 2016;20(1):614. https://doi.org/10.3109/10903127.2015.1025157.

18. Horibata K, Takemura Y. Inappropriate use of ambulance services by elderly patients with less urgent medical needs. Tohoku J Exp Med. 2015;235(2):8995. https://doi.org/10.1620/tjem.235.89.

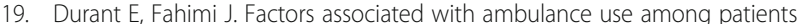
with low-acuity conditions. Prehosp Emerg Care. 2012;16(3):329-37. https:// doi.org/10.3109/10903127.2012.670688.

20. Shenvi CL, Platts-Mills TF. Managing the elderly emergency department patient. Ann Emerg Med. 2019;73(3):302-7. https://doi.org/10.1016/j. annemergmed.2018.08.426.

21. Duong HV, Herrera LN, Moore JX, Donnelly J, Jacobson KE, Carlson JN, et al. National characteristics of emergency medical services responses for older adults in the United States. Prehosp Emerg Care. 2018;22(1):7-14. https:// doi.org/10.1080/10903127.2017.1347223.

22. Magnusson C, Herlitz J, Axelsson C. Patient characteristics, triage utilisation, level of care, and outcomes in an unselected adult patient population seen by the emergency medical services: a prospective observational study. BMC Emerg Med. 2020;20(1):7. https://doi.org/10.1186/s12873-020-0302-x.

23. Statistics Sweden. Urban areas (localities); 2018. https://www.scb.se/ contentassets/745b357fd3b74ffd934fc4004ce5cf62/mi0810_2018a01_sm_ mi38sm1901.pdf. Accessed 20 Jan 2020.

24. Statistics Sweden. Population by region, marital status, age and sex. Year 1968-2019: http://www.statistikdatabasen.scb.se/pxweb/en/ssd/START_ BE BE0101_BE0101A/BefolkningNy/Accessed 17 Apr 2020.

25. Lindström V, Bohm K, Kurland L. Prehospital care in Sweden. Notfall + Rettungsmedizin. 2015;18(2):107-9. https://doi.org/10.1007/s10049-015-1989-1.

26. Carlström $E$, Fredén $L$. The first single responders in Sweden - evaluation of a pre-hospital single staffed unit. Int Emerg Nurs. 2017;32:15-9. https://doi. org/10.1016/j.ienj.2016.05.003

27. Widgren BR, Jourak M. Medical emergency triage and treatment system (METTS): a new protocol in primary triage and secondary priority decision in emergency medicine. J Emerg Med. 2011;40(6):623-8. https://doi.org/10 1016/j.jemermed.2008.04.003

28. SOSFS 2009:10. Socialstyrelsens författningssamling. Ambulanssjukvård. [the national board of health and welfare. Code of statues. Prehospital emergency care]. 2009. Stockholm: Socialstyrelsen.

29. Lowthian J, Curtis A, Stoelwinder J, McNeil J, Cameron P. Emergency demand and repeat attendances by older patients. Intern Med J. 2013;43: 554-60. https://doi.org/10.1111/imj.12061.

30. Wireklint SC, Elmqvist C, Parenti N, Göransson KE. A descriptive study of registered nurses' application of the triage scale RETTSO; a Swedish reliability study. Int Emerg Nurs. 2018;38:21-8. https://doi.org/10.1016/j.ienj. 2017.12.003

31. Lederman J, Löfvenmark C, Djärv T, Lindström V, Elmqvist C. Assessing nonconveyed patients in the ambulance service: a phenomenological interview study with Swedish ambulance clinicians. BMJ Open. 2019;9:e030203. https://doi.org/10.1136/bmjopen-2019-030203.

32. Höglund E, Schröder A, Möller M, Andersson-Hagiwara M, Ohlsson-Nevo E. The ambulance nurse experiences of non-conveying patients. J Clin Nurs. 2018:00:1-10. https://doi.org/10.1111/jocn.14626.

33. Oosterwold J, Sagel D, Berben S, Roodbol P, Broekhuis M. Factors influencing the decision to convey or not to convey elderly people to the emergency department after emergency ambulance attendance: a systematic mixed studies review. BMJ Open. 2018;8:e021732. https://doi.org/ 10.1136/bmjopen-2018-021732.

34. Yeung T, Shannon B, Perillo S, Nehme Z, Jennings P, Olaussen A. Review article: outcomes of patients who are not transported following ambulance 
attendance: a systematic review and meta-analysis. Emerg Med Australas. 2019;31:321-31. https://doi.org/10.1111/1742-6723.13288.

35. O'Hara R, Johnson M, Siriwardena AN, Weyman A, Turner J, Shaw D, et al. A qualitative study of systemic influences on paramedic decision making: care transitions and patient safety. J Health Serv Res Policy. 2015;20:45-53. https://doi.org/10.1177/1355819614558472.

36. SBU [Swedish Council on Health Technology Assessment]. Omhändertagande av äldre som inkommer akut till sjukhus - med fokus på sköra äldre. Stockholm: Statens beredning för medicinsk utvärdering (SBU); 2013. SBU-rapport nr 221. ISBN 978-91-85413-62-1.

37. Bunn JG, Croft SJ, O'Keeffe C, Jacques RM, Simpson RM, Stone T, et al. Urgent care axis for the older adult: where is best to target interventions? Emerg Med J. 2019;36:22-6. https://doi.org/10.1136/emermed-2018-207505.

38. Kennelly SP, Drumm B, Coughlan T, Collins R, O'Neill D, Romero-Ortuno R. Characteristics and outcomes of older persons attending the emergency department: a retrospective cohort study. Q J Med. 2014;107:977-87. https://doi.org/10.1093/qjmed/hcu111.

39. Hwang U, Morrison RS. The geriatric emergency department. J Am Geriatr Soc. 2007;55(11):1873-6. https://doi.org/10.1111/j.1532-5415.2007.01400.x.

40. Dugaret E, Videau MN, Faure I, Gabinski C, Bourdel-Marchasson I, Salles N. Prevalence and incidence rates of pressure ulcers in an emergency department. Int Wound J. 2014;11:386-91. https://doi.org/10.1111/j.1742481X.2012.01103.x.

41. Vicente V, Castren M, Sjöstrand F, Wireklint SB. Elderly patients' participation in emergency medical services when offered an alternative care pathway. Int J Qual Stud Health Well-being. 2013;8:20014. https://doi.org/10.3402/ ghw.v8i0.20014

42. Bridges J, Flatley M, Meyer J. Older people's and relatives' experiences in acute care settings: systematic review and synthesis of qualitative studies. Int J Nurs Stud. 2010;47:89-107. https://doi.org/10.1016/j.ijnurstu.2009.09.009.

43. Olofsson P, Carlström ED, Back-Pettersson S. During and beyond the triage encounter: chronically ill elderly patients' experiences throughout their emergency department attendances. Int Emerg Nurs. 2012;20:207-13. https://doi.org/10.1016/j.ienj.2012.03.006.

44. Barrientos $C$, Holmberg $M$. The care of patients assessed as not in need of emergency ambulance care - registered nurses' lived experiences. Int Emerg Nurs. 2018;38:10-4. https://doi.org/10.1016/j.ienj.2018.01.007.

45. Booker MJ, Purdy S, Shaw ARG. Seeking ambulance treatment for 'primary care' problems: a qualitative systematic review of patient, carer and professional perspectives. BMJ Open. 2017;7:e016832. https://doi.org/10. 1136/bmjopen-2017-016832.

46. Chan DKY, Liu FX, Irwanto D, Prasetyo D, Ozorio G, Li F, et al. Experience of establishing an acute geriatric outreach service versus subacute service to nursing homes. Intern Med J. 2018;48:1396-9. https://doi.org/10.1111/imj. 14104.

47. Hogan TM, Richmond NL, Carpenter CR, Biese K, Hwang U, Shah MN, et al. Shared decision making to improve the emergency Care of Older Adults: a research agenda. Acad Emerg Med. 2016;23(12):1386-93. https://doi.org/10. 1111/acem.13074.

48. Larsson G, Holmen A, Ziegert K. Early prehospital assessment of non-urgent patients and outcomes at the appropriate level of care: a prospective exploratory study. Int Emerg Nurs. 2017;32:45-9. https://doi.org/10.1016/j. ienj.2017.02.003.

49. Yip $W L$, Fan $K L$, Lui $C T$, Leung LP, Ng F, Tsui KL. Utilization of the Accident \& Emergency Departments by Chinese elderly in Hong Kong. World J Emerg Med. 2015;6:283-8. https://doi.org/10.5847/wjem.j.1920-8642.2015.04.006.

50. Christensen EF, Bendtsen MD, Larsen TM, Jensen FB, Lindskou TA, Holdgaard $\mathrm{HO}$, et al. Trends in diagnostic patterns and mortality in emergency ambulance service patients in 2007-2014: a population-based cohort study from the North Denmark region. BMJ Open. 2017;7:e014508. https://doi.org/10.1136/bmjopen-2016-014508

51. Vloet LCM, de Kreek A, van der Linden EMC, van Spijk JJA, Theunissen VAH, van Wanrooij M, et al. A retrospective comparison between non-conveyed and conveyed patients in ambulance care. Scand J Trauma Resusc Emerg Med. 2018;26:91. https://doi.org/10.1186/s13049-018-0557-3.

52. Mills TL. Comorbid depressive symptomatology: isolating the effects of chronic medical conditions on self-reported depressive symptoms among community-dwelling older adults. Soc Sci Med. 2001;53:569-78. https://doi. org/10.1016/S0277-9536(00)00361-0.

53. Fässberg MM, Cheung G, Canetto SS, Erlangsen A, Lapierre S, Lindner R, et al. A systematic review of physical illness, functional disability, and suicidal behaviour among older adults. Aging Ment Health. 2016;20:166-94. https://doi.org/10.1080/13607863.2015.1083945.

54. Voss S, Brandling J, Taylor H, Black S, Buswell M, Cheston R, et al. How do people with dementia use the ambulance service? A retrospective study in England: the HOMEWARD project. BMJ Open. 2018;8:e022549. https://doi. org/10.1136/bmjopen-2018-022549.

55. Harmsen AMK, Giannakopoulos GF, Moerbeek PR, Jansma EP, Bonjer HJ, Bloemers FW. The influence of prehospital time on trauma patients outcome: a systematic review. Injury. 2015;46:602-9. https://doi.org/10.1016/ j.injury.2015.01.008.

56. Cantwell K, Burgess S, Morgans A, Smith K, Livingston M, Dietze P. Temporal trends in falls cases seen by EMS in Melbourne: the effect of residence on time of day and day of week patterns. Injury. 2016;47:266-71. https://doi. org/10.1016/j.injury.2015.10.073.

\section{Publisher's Note}

Springer Nature remains neutral with regard to jurisdictional claims in published maps and institutional affiliations.
Ready to submit your research? Choose BMC and benefit from:

- fast, convenient online submission

- thorough peer review by experienced researchers in your field

- rapid publication on acceptance

- support for research data, including large and complex data types

- gold Open Access which fosters wider collaboration and increased citations

- maximum visibility for your research: over $100 \mathrm{M}$ website views per year

At BMC, research is always in progress.

Learn more biomedcentral.com/submissions 